\title{
Cucurbit[n]uril binding of platinum anticancer complexes $\dagger$
}

\author{
Nial J. Wheate, + Damian P. Buck, Anthony I. Day and J. Grant Collins* \\ Received 16th September 2005, Accepted 10th November 2005 \\ First published as an Advance Article on the web 28th November 2005 \\ DOI: 10.1039/b513197a
}

\begin{abstract}
The encapsulation of cisplatin by cucurbit[7]uril (Q[7]) and multinuclear platinum complexes linked via a 4,4'-dipyrazolylmethane (dpzm) ligand by Q[7] and cucurbit[8]uril (Q[8]) has been studied by NMR spectroscopy and molecular modelling. The NMR studies suggest that some cisplatin binds in the cucurbituril cavity, while cis- $\left[\mathrm{PtCl}\left(\mathrm{NH}_{3}\right)_{2}\left(\mathrm{H}_{2} \mathrm{O}\right)\right]^{+}$only binds at the portals. Alternatively, the dpzm-linked multinuclear platinum complexes are quantitatively encapsulated within the cavities of both Q[7] and Q[8]. Upon encapsulation, the non-exchangeable proton resonances of the multinuclear platinum complexes show significant upfield shifts in ${ }^{1} \mathrm{H}$ NMR spectra. The $\mathrm{H} 3 / \mathrm{H} 3 *$ resonances shift upfield by 0.08 to $0.55 \mathrm{ppm}$, the $\mathrm{H} 5 / \mathrm{H} 5 *$ shift by 0.9 to $1.6 \mathrm{ppm}$, while the methylene resonances shift by 0.74 to $0.88 \mathrm{ppm}$. The size of the resonance shift is dependent on the cavity size of the encapsulating cucurbituril, with Q[7] encapsulation producing larger shifts than Q[8]. The upfield shifts of the dpzm resonances observed upon cucurbituril encapsulation indicate that the Q[7] or Q[8] is positioned directly over the dpzm linking ligand. The terminal platinum groups of trans- $\left[\left\{\mathrm{PtCl}\left(\mathrm{NH}_{3}\right)_{2}\right\}_{2} \mu-\mathrm{dpzm}\right]^{2+}$ (di-Pt) and trans- $\left[\text { trans- }\left\{\mathrm{PtCl}\left(\mathrm{NH}_{3}\right)_{2}\right\}_{2} \text {-trans- }\left\{\mathrm{Pt}(\mathrm{dpzm})_{2}\left(\mathrm{NH}_{3}\right)_{2}\right\}\right]^{4+}$ (tri-Pt) provide a barrier to the on and off movement of cucurbituril, resulting in binding kinetics that are slow on the NMR timescale for the metal complex. Although the dpzm ligand has relatively few rotamers, encapsulation by the larger $\mathrm{Q}[8]$ resulted in a more compact di-Pt conformation with each platinum centre retracted further into each Q[8] portal. Encapsulation of the hydrolysed forms of di-Pt and tri-Pt is considerably slower than for the corresponding $\mathrm{Cl}$ forms, presumably due to the high-energy cost of passing the +2 platinum centres through the cucurbituril portals. The results of this study suggest that cucurbiturils could be suitable hosts for the pharmacological delivery of multinuclear platinum complexes.
\end{abstract}

\section{Introduction}

Cisplatin is an effective drug in the treatment of human testicular, ovarian, lung, bladder, head and neck cancers. ${ }^{1}$ The continued use of cisplatin, however, is limited by both natural and acquired resistance. $^{2}$ This resistance can arise from several factors which include: drug deactivation by increased intracellular glutathione levels, reduced cellular uptake, enhanced DNA repair and/or increased tolerance of platinum-DNA lesions. ${ }^{3}$ In addition, cisplatin is limited by its side-effects, which include neuro- and nephrotoxicity, nausea and vomiting. These side-effects limit the drug to doses between 60 and $120 \mathrm{mg} \mathrm{m}^{-2}$.

Much of the synthetic research over the last 20 years has focused on drugs that are able to overcome both resistance and the dose-limiting side-effects. ${ }^{5-9}$ This has led to the approval of carboplatin and oxaliplatin for clinical use ${ }^{3}$ and the development of multinuclear platinum complexes. ${ }^{10-18}$

Multinuclear platinum complexes are thought to overcome resistance through novel DNA binding modes. ${ }^{14-19}$ Whereas cisplatin and carboplatin mostly form rigid, short-range intrastrand DNA

School of Physical, Environmental and Mathematical Sciences, University College, University of New South Wales, Australian Defence Force Academy, Canberra, ACT, 2600, Australia.E-mail: g-collins@adfa.edu.au; Fax: +61 (02) 62688002

$\dagger$ Electronic supplementary information (ESI) available: Colour versions of Fig. 8 and 9. See DOI: 10.1039/b513197a

† Current address: School of Science, Food and Horticulture, University of Western Sydney, Campbelltown, NSW, 2560, Australia. adducts, the multinuclear complexes are generally identified as forming flexible, long-range interstrand adducts. ${ }^{14-19}$ In addition, these complexes are taken up by cells to a greater extent than cisplatin. ${ }^{20-29}$ Particularly important features of multinuclear platinum drugs are their ability to overcome both natural and acquired resistance and show activity in cancers that are defined as p53mutant. ${ }^{30-33}$

One such complex, BBR3464 (Fig. 1) has entered phase II clinical trials and three other complexes, BBR3571, BBR3610 and BBR3611 have shown strong clinical potential. ${ }^{3,17,34-38}$ While these complexes are active at concentrations 10- to 100-fold lower than cisplatin, they are also more toxic. From phase I trials the maximum tolerated dose of BBR3464 was found to be between 0.9 and $1.1 \mathrm{mg} \mathrm{m}^{-2}$, while other BBR complexes appear to be even more toxic. ${ }^{35-38}$ Recent trials have also shown that these complexes may be degraded (and hence deactivated) by plasma proteins before they reach their intracellular target; possibly explaining the low activity of BBR3464 in phase II trials to date. ${ }^{35-38}$

Recently, our group has identified a mechanism by which both the toxicity of these drugs could be decreased, and their degradation reduced within the human body. ${ }^{39}$ Cucurbit $[n]$ uril $(\mathrm{Q}[n])$ is a barrel-shaped molecule, containing a hydrophobic cavity, formed by the acid catalysed condensation of glycoluril and formaldehyde (Fig. 1). ${ }^{40-44}$ Cucurbit $[n]$ urils can be synthesised in a variety of sizes $(n=5,6,7,8$ and 10), and are capable of encapsulating smaller molecules within their cavities. ${ }^{45-48}$ In the case of cucurbit[7]uril (Q[7]) we have shown that its encapsulation of the dinuclear platinum complex trans- $\left[\left\{\mathrm{PtCl}\left(\mathrm{NH}_{3}\right)\right\}_{2} \mu \text {-dpzm }\right]^{2+}$ 


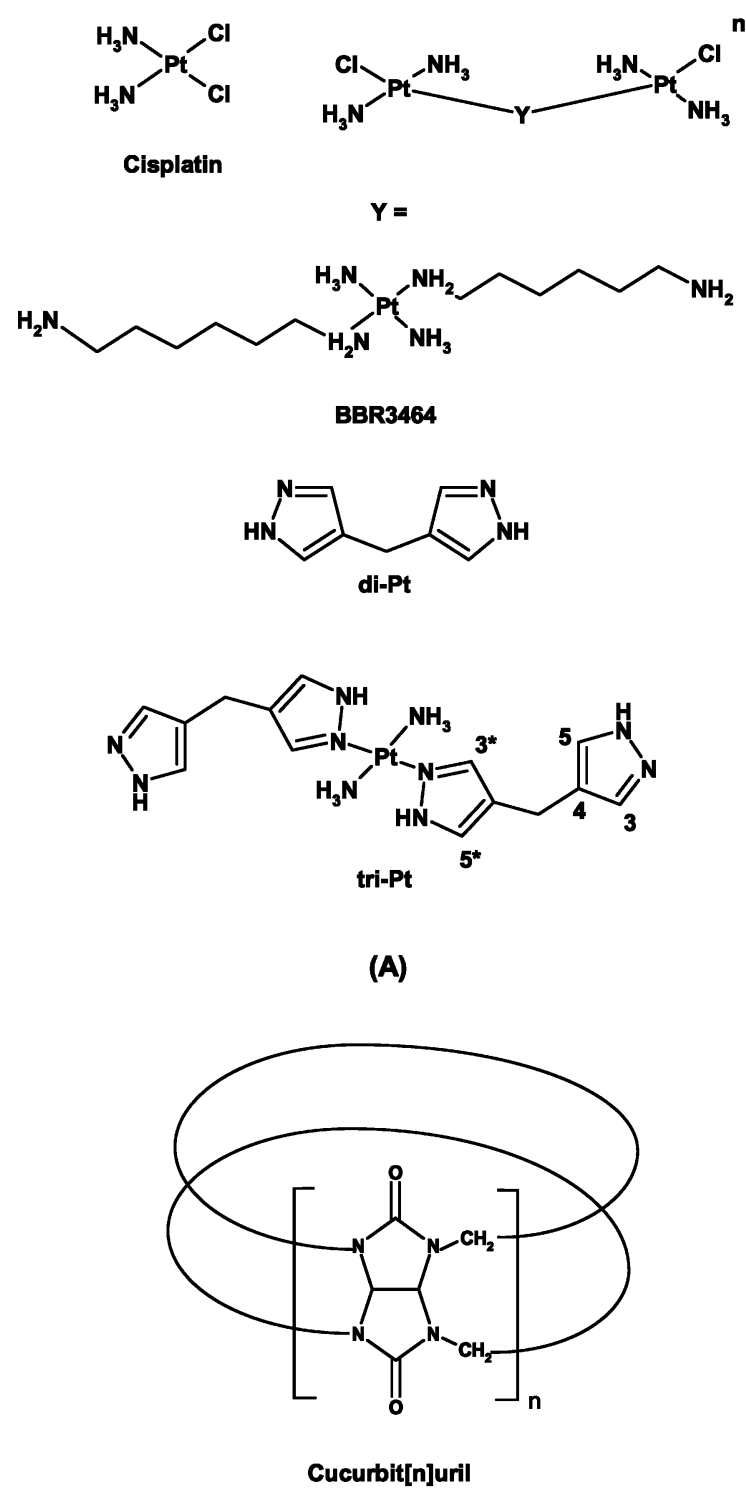

(B)

Fig. 1 (A) Structure of cisplatin and a generic multinuclear platinum complex with a range of linking ligands that yield: BBR3463; di-Pt and tri-Pt and (B) cucurbit $[n]$ uril.

(di-Pt, Fig. 1) slows the platinum complex's rate of reaction with guanosine, without affecting its normal DNA binding mode or its in vitro cytotoxicity. ${ }^{39}$ In contrast, other researchers have shown that the encapsulation of oxaliplatin with Q[7] reduced the drugs reactivity to both guanosine and methionine, but that in vitro cytotoxicity was also reduced. ${ }^{49}$

In this study, we extend our previous preliminary report of the encapsulation of di-Pt by Q[7]. ${ }^{39}$ We have studied encapsulation by $\mathrm{Q}[7]$ and $\mathrm{Q}[8]$ of cisplatin, di-Pt and the related trinuclear complex trans $-\left[\text { trans }-\left\{\mathrm{PtCl}\left(\mathrm{NH}_{3}\right)_{2}\right\}_{2}-\text { trans }-\left\{\mathrm{Pt}(\mathrm{dpzm})_{2}\left(\mathrm{NH}_{3}\right)_{2}\right\}\right]^{4+}$ (tri-Pt) (see Fig. 1). These were studied by NMR spectroscopy and molecular modelling in an effort to achieve a more detailed understanding of the relationship of the host to the guest in a potential protective drug delivery vehicle role.

\section{Experimental}

\section{Materials}

Transplatin, cisplatin, pyrazole, tetrabutylammonium hydroxide were purchased from the Aldrich Chemical Company. $\mathrm{D}_{2} \mathrm{O}$ was purchased from Cambridge Isotope Laboratories. Q[7], $\mathrm{Q}[8]$ and the metal complexes were synthesised as previously described. ${ }^{20,40,50,51}$ Aqua forms of the metal complexes were prepared by the addition of 2 mol equivalents of $\mathrm{AgNO}_{3}$ as an aqueous solution. The resultant $\mathrm{AgCl}$ was removed by centrifugation and the resulting solution freeze dried to remove water before dissolution in $\mathrm{D}_{2} \mathrm{O}$. All solvents were used as provided and aqueous solutions were made using Milli-Q water, coming from a Millipore four-stage water purification unit.

\section{Encapsulation of platinum complexes}

The encapsulated platinum complexes were obtained by either direct crystallisation (1) or by titration of the metal complex into a cucurbituril solution (2). (1) Equimolar, or in some cases a two- or three-fold excess of cucurbituril, amounts of the platinum complex and cucurbituril were dissolved in hot water containing $20 \mathrm{mM}$ $\mathrm{NaCl}$. Slow evaporation of the solution resulted in crystals of cucurbituril-encapsulated metal complexes. (2) Aliquots of the platinum complex dissolved in $\mathrm{D}_{2} \mathrm{O}$ (approx. $2 \mathrm{mM}$ ) were directly titrated into a 5 to $10 \mathrm{~mL}$ solution of the appropriate cucurbituril (2-4 mM) in $\mathrm{D}_{2} \mathrm{O}$ to give the desired molar ratio. Aliquots of the solution were then taken for analysis by NMR spectroscopy.

\section{NMR}

1D and 2D NMR spectra were obtained on a Varian Unityplus400 spectrometer operating at $400 \mathrm{MHz}$ for ${ }^{1} \mathrm{H}$ and $85 \mathrm{MHz}$ for ${ }^{195} \mathrm{Pt}$. 1D ${ }^{1} \mathrm{H}$ NMR spectra were recorded over a spectral width of $5000 \mathrm{~Hz}$ using 256 transients. 2D NOESY spectra were obtained over a spectral width of $4200 \mathrm{~Hz}$ with a mixing time of $300 \mathrm{~ms}$ using 2048 points in the $t_{2}$ dimension with $256 t_{1}$ increments and with a total recycle time of $1.7 \mathrm{~s}$. All ${ }^{1} \mathrm{H}$ NMR were referenced to DSS $(0 \mathrm{ppm})$ at $25^{\circ} \mathrm{C} .{ }^{195} \mathrm{Pt} \mathrm{NMR}$ were externally referenced to $\mathrm{K}_{2} \mathrm{PtCl}_{4}$ $(-1631 \mathrm{ppm})$ and collected using a spectral width between 75000 and $100000 \mathrm{~Hz}$, with between 1000 and 10000 transients and a recycle time of $0-0.4 \mathrm{~s}$.

\section{Molecular modelling}

Encapsulated multinuclear complexes were modelled using HyperChem 7.5. ${ }^{52}$ Energy restraints were applied to the bond angles of complexes to maintain square-planar geometries under a molecular mechanics (MM+) forcefield, and were minimised to a root-mean-square gradient of $0.2 \mathrm{~kJ}^{-1} \mathrm{~mol}^{-1}$. Cisplatin charge distribution was based on the ab initio analysis of Pavankumar et al. ${ }^{53}$ Charges of multinuclear complexes were distributed evenly among the ligands, and the chloride ligand charge distribution was based on the molecular mechanics analysis of other $\mathrm{Pt}$ (II) compounds by Battle et al. ${ }^{54}$ The complexes were modelled in different starting orientations. The energies were calculated for comparison using $\mathrm{MM}+$ with the energy restraints removed. 


\section{Results}

\section{Encapsulation of cisplatin}

Although the primary focus of our research is the encapsulation of multinuclear platinum anticancer drugs, it was of interest to examine the interaction of cisplatin with cucurbituril. Cisplatin is a charge neutral complex unlike the multinuclear platinum drugs. Hence, it was anticipated that cisplatin encapsulation would be different but relevant to the understanding of the encapsulation of multinuclear platinum drugs. Consequently, the interaction between Q[7] and cisplatin was studied by ${ }^{1} \mathrm{H}$ and ${ }^{195} \mathrm{Pt}$ NMR. Fig. 2 shows the ${ }^{1} \mathrm{H}$ NMR spectrum of Q[7] and Q[7] with added cisplatin in a metal complex to cucurbituril ratio $(R)$ of 1 . Upon addition of cisplatin, the Q[7]-CH resonance at $5.58 \mathrm{ppm}$ splits into two peaks (5.63 and $5.55 \mathrm{ppm}$ ). One resonance is shifted marginally upfield and exhibits significant line broadening, while the other resonance is relatively sharp and is shifted marginally downfield. A similar pattern for the resonances from the nonequivalent Q[7]- $\mathrm{CH}_{2}$ protons is also observed. The broadened and shifted resonances are consistent with one (or more) bound form being in fast to intermediate exchange with free Q[7], with another cisplatin bound form being in slow exchange (sharp resonances) with the free cucurbituril and the other bound form(s).

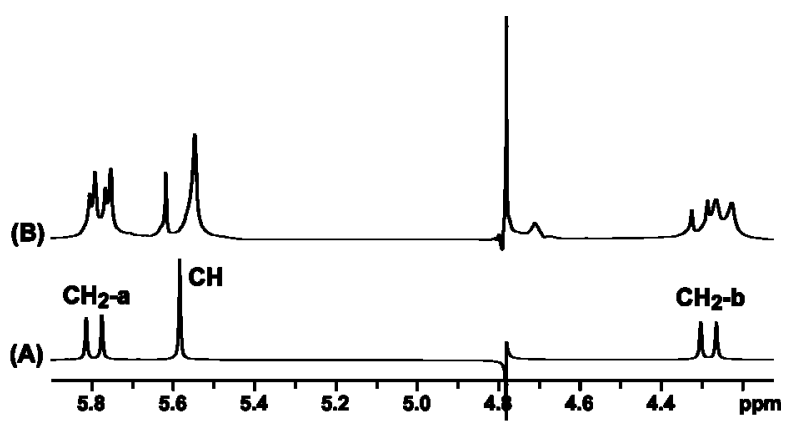

Fig. $2{ }^{1} \mathrm{H}$ NMR spectra showing (A) Q[7] and (B) Q[7] with added cisplatin at $R=1$ in $\mathrm{D}_{2} \mathrm{O}$ at $25^{\circ} \mathrm{C}$.

It is normal for an equilibrium to be established between the chloro- and aqua-forms of cisplatin when the platinum complex is dissolved in slightly acidic water (Fig. 3A), with $\mathrm{Pt}$ resonances for $c i s-\left[\mathrm{PtCl}_{2}\left(\mathrm{NH}_{3}\right)_{2}\right]$ and $c i s-\left[\mathrm{PtCl}\left(\mathrm{NH}_{3}\right)_{2}\left(\mathrm{H}_{2} \mathrm{O}\right)\right]^{+}$being observed at -2160 and $-1854 \mathrm{ppm}$ respectively, consistent with literature values. ${ }^{55}$ Both of these forms of cisplatin can associate with Q[7]. Upon addition of Q[7] a second resonance is observed in the region of the chloro form at $-2109 \mathrm{ppm}$, while the resonance due to the

(B)

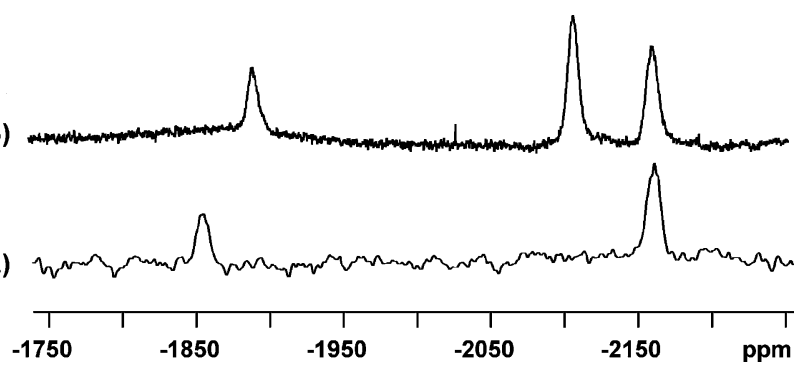

Fig. $3{ }^{195} \mathrm{Pt}$ NMR spectra showing (A) cisplatin and (B) cisplatin with added $\mathrm{Q}[7]$ at $R=1$ in $\mathrm{D}_{2} \mathrm{O}$ at $25^{\circ} \mathrm{C}$. aqua form has significantly shifted to $-1890 \mathrm{ppm}$ (see Fig. 3B). A single resonance for the aqua form may suggest quantitative binding to Q[7] with slow exchange kinetics, or more likely, binding with fast to intermediate exchange (on the ${ }^{195} \mathrm{Pt}$ NMR time scale). More significantly, the observation of separate resonances for free and bound chloro forms indicates slow exchange kinetics, suggesting that a fraction of the chloro form of cisplatin binds inside Q[7]. Encapsulation of cisplatin by Q[7] is consistent with the reported crystal structure of the metal complex cis- $\left[\mathrm{SnCl}_{4}\left(\mathrm{OH}_{2}\right)_{2}\right]$ encapsulated by Q[7]. ${ }^{45}$ Whereas, the $c i s-\left[\mathrm{PtCl}\left(\mathrm{NH}_{3}\right)_{2}\left(\mathrm{H}_{2} \mathrm{O}\right)\right]^{+}$complex would be expected to bind only to the portal of Q[7], where it can maximise the electrostatic interactions and possibly form hydrogen bonds.

\section{Encapsulation of di-Pt}

Fig. 4 shows the ${ }^{1} \mathrm{H}$ NMR spectrum of free di-Pt (A) and di-Pt with added $\mathrm{Q}$ [7] (B). The assignments of the resonances from the metal complex were made from NOESY experiments and depth profiling. ${ }^{56}$ Molecular models of the Q[7]-encapsulated di$\mathrm{Pt}$ complex indicated that the dpzm $\mathrm{H} 3$ protons were closer to the dpzm methylene protons than the H5. It was predicted from the distances to the methylene protons that the NOE to $\mathrm{H} 3$ would be 1.4 times more intense than that to $\mathrm{H} 5$. Hence, $\mathrm{H} 3$ was assigned to the downfield resonance $(\sim 7.3 \mathrm{ppm})$ with the strongest NOE from the dpzm methylene protons $(\sim 3.0 \mathrm{ppm})$. The upfield resonance at $\sim 6.3 \mathrm{ppm}$ was assigned to $\mathrm{H} 5$. The encapsulation model (see below) indicated that any NOE cross-peaks observed between dpzm and Q[7] protons would be significantly weaker than those observed between protons within the dpzm ligand, because the Q[7] protons project away from the cucurbituril cavity. While several very weak intermolecular NOE cross-peaks were observed in long mixing time NOESY spectra between dpzm and Q[7] protons, they could not be used to provide any quantitative distance information. However, the lack of strong intermolecular

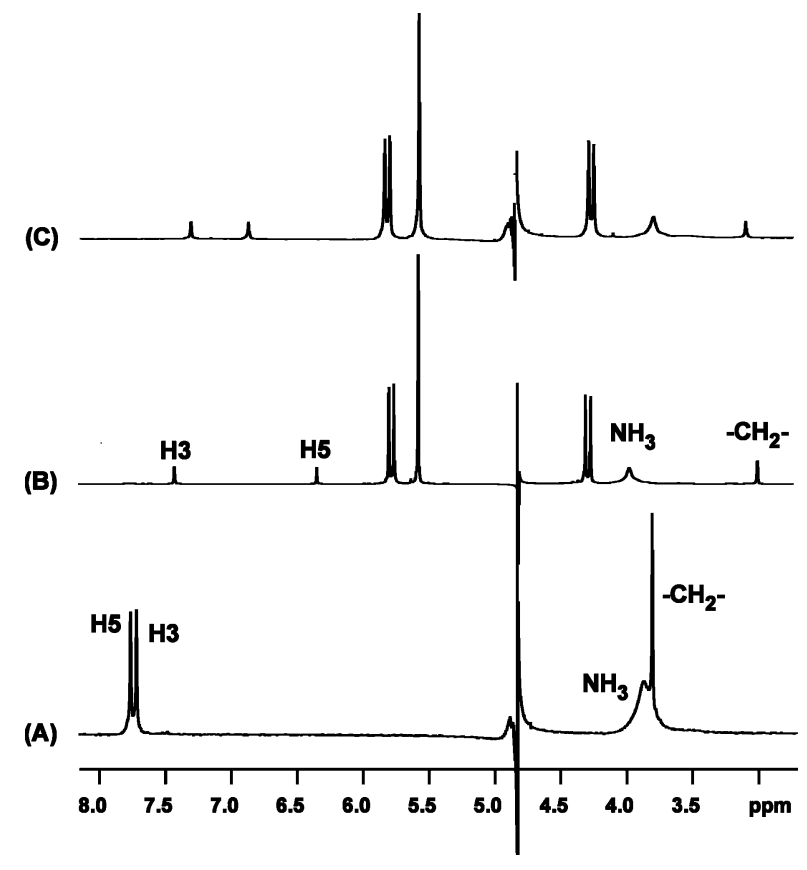

Fig. $4{ }^{1} \mathrm{H}$ NMR spectra showing (A) di-Pt and (B) di-Pt with added Q[7] at $R=1$ and (C) di-Pt with added Q[8] at $R=1$ in $\mathrm{D}_{2} \mathrm{O}$ at $25^{\circ} \mathrm{C}$. 
Table $1{ }^{1} \mathrm{H}$ NMR chemical shifts of the platinum complexes di-Pt and tri-Pt encapsulated by Q[7] and Q[8], and the change in chemical shift from the free metal complex in brackets (negative numbers indicate upfield shifts)

\begin{tabular}{llllll}
\hline & \multicolumn{2}{l}{ Chemical shift $(\mathrm{ppm})$} & & \\
\cline { 2 - 6 } Complex & $\mathrm{H} 5$ & $\mathrm{H} 5^{*}$ & $\mathrm{H} 3$ & $\mathrm{H}{ }^{*}$ & $\mathrm{CH}_{2-}$ \\
\hline di-Pt-Q[7] & $6.29(-1.49)$ & $a$ & $7.37(-0.37)$ & $a$ & $2.94(-0.88)$ \\
di-Pt-[Q8] & $6.84(-0.94)$ & $a$ & $7.28(-0.46)$ & $a$ & $3.06(-0.76)$ \\
tri-Pt-Q[7] & $6.32(-1.54)$ & $6.48(-1.36)$ & $7.30(-0.53)$ & $7.71(-0.08)$ & $3.02(-0.84)$ \\
tri-Pt-Q[8] & $6.84(-1.02)$ & $7.05(-0.79)$ & $7.23(-0.60)$ & $7.44(-0.35)$ & $3.12(-0.74)$
\end{tabular}

${ }^{a}=$ Not applicable.

NOE interactions is consistent with the proposed encapsulation model. From experiments with Q[6] and various aminoalkanes it was found that the protons further inside Q[6] exhibited the greatest upfield shift in the ${ }^{1} \mathrm{H}$ NMR spectra due to shielding effects. ${ }^{56}$ Furthermore, protons that on average are located outside but near the portal exhibit slight downfield shifts. ${ }^{56,57}$ Molecular models indicated that the $\mathrm{H} 5$ proton is further inside Q[7] than $\mathrm{H} 3$ (see below), and hence showed the largest upfield shift of $1.49 \mathrm{ppm}$ (see Table 1).

As separate resonances for the free and Q[7]-encapsulated di-Pt were observed at $R>1$ (results not shown), it is concluded that the metal complex binds with slow exchange kinetics on the NMR time scale.

The resonances from the Q[8]-bound di-Pt (Fig. 4C) were assigned using molecular modelling and depth profiling. Models of di-Pt encapsulated in Q[8] indicated that that the distances from the $\mathrm{H} 3$ and $\mathrm{H} 5$ protons to the dpzm methylene protons were very similar, and hence assignments could not be obtained from a NOESY spectrum. However, changes in the chemical shifts of the resonances from di-Pt suggested Q[8]-encapsulation was again centred on the dpzm linker rather than the platinum centres. Consequently, the $\mathrm{H} 3$, which is closer to the platinum centre, will be located less deeply in the Q[8] cavity, regardless of the pyrazolyl-methylene torsion angles. Therefore, the upfield resonance $(6.64 \mathrm{ppm})$ is again assigned to the $\mathrm{H} 5$, with downfield resonance at $7.28 \mathrm{ppm}$ being assigned to the $\mathrm{H} 3$.

Encapsulation of di-Pt by Q[8] induced large upfield shifts of the dpzm resonances (see Fig. 4C), with the di-Pt H3 and methylene resonances shifting by a similar amount to that observed for Q[7]encapsulation; however, the $\mathrm{H} 5$ resonance shifted upfield by only $0.94 \mathrm{ppm}$ compared to $1.49 \mathrm{ppm}$ for Q[7]-encapsulation. This indicates that the platinum complex is positioned, on average, differently in Q[8] than in Q[7]. In addition, the resonance due to the remaining unexchanged (with the $\mathrm{D}_{2} \mathrm{O}$ ) ammine protons of di-Pt shifted downfield upon Q[7]-encapsulation and upfield upon Q[8]-encapsulation. This suggests that the ammine protons are located on average deeper into the portal opening of $\mathrm{Q}[8]$, but outside and near the portal of Q[7]. Although it can not be clearly seen in Fig. 4, the dpzm resonances of the Q[8]encapsulated di-Pt are significantly broader than was observed for Q[7]-encapsulation, e.g. the width at half-height of the H3 resonance is $2.5 \mathrm{~Hz}$ and $9.7 \mathrm{~Hz}$ for Q[7]- and Q[8]-encapsulation respectively. This suggests that the exchange rate between the Q[8]encapsulated di-Pt and the free metal complex is faster than for Q[7]-encapsulation, consistent with the increased portal size.

The ${ }^{1} \mathrm{H}$ NMR spectrum for the hydrolysed-form of di-Pt and the hydrolysed-form of di-Pt with added Q[7] as a function of time after mixing is shown in Fig. 5. Prior to encapsulation with Q[7], complete hydrolysis of di-Pt was confirmed by ${ }^{195} \mathrm{Pt}$ NMR. The Pt resonance of di-Pt at $-2327 \mathrm{ppm}$ was absent and a resonance for the aqua complex observed at $-2042 \mathrm{ppm}$. As expected, large upfield shifts of the resonances in the ${ }^{1} \mathrm{H}$ NMR spectra are observed for the dpzm resonances, indicating the hydrolysed di-Pt is also encapsulated by Q[7]; however, almost 24 hours are required for all the platinum complex to be encapsulated. Whereas, di-Pt $(\mathrm{Cl}$ form) is rapidly encapsulated by Q[7] (less than the time required for mixing and accumulation of the ${ }^{1} \mathrm{H}$ NMR spectrum). This indicates that it is considerably more difficult for the +2 platinum centre obtained upon hydrolysis of di-Pt to pass through the Q[7] portal.

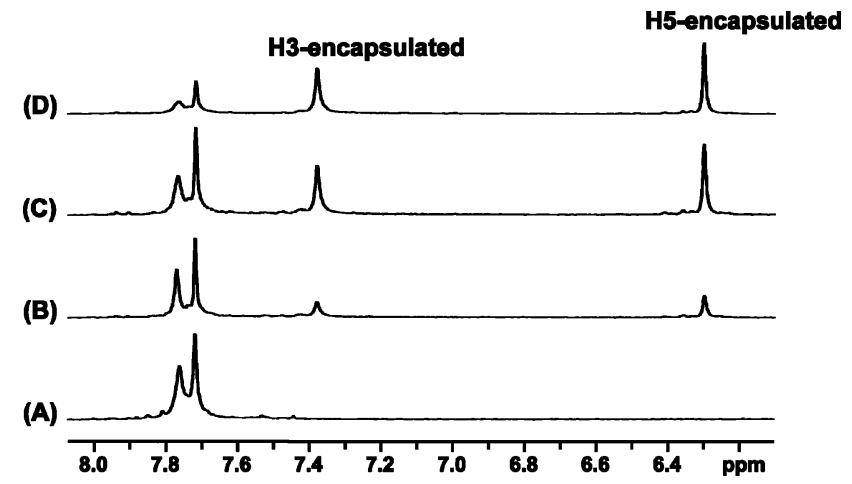

Fig. $5{ }^{1} \mathrm{H}$ NMR spectra showing (A) the hydrolysed form of di-Pt and with added Q[7] (B) 30 min, (C) 8 hours and (D) 15 hours after mixing.

\section{Encapsulation of tri-Pt}

Fig. 6 shows the ${ }^{1} \mathrm{H}$ NMR spectrum of free tri-Pt and tri-Pt with added Q[7] and Q[8] at $R=0.5$ (i.e. 2 cucurbiturils per platinum complex). At $R=0.5$ each linking dpzm ligand was encapsulated. Encapsulation by either Q[7] or Q[8] induces significant upfield shifts for the tri-Pt resonances (see Table 1), with the H5/H5* resonances exhibiting greater shifts than the $\mathrm{H} 3 / \mathrm{H} 3 *$ resonances, as was observed for di-Pt encapsulation. The magnitude of the shifts for the $\mathrm{H} 5 / \mathrm{H} 5 *$ and $\mathrm{H} 3 / \mathrm{H} 3$ * resonances upon $\mathrm{Q}[7]$ and $\mathrm{Q}[8]$ encapsulation is different, indicating that tri-Pt adopts a different binding orientation with Q[7] compared to Q[8]. Upon encapsulation of tri-Pt, the Q[7] resonance at $5.8 \mathrm{ppm}$ splits into two doublets, indicating that the initially symmetric pair of protons (one from each $\mathrm{CH}_{2}$ ) of the cucurbituril are non-equivalent. This loss of symmetry is presumably due to the different nature of the terminal and central platinum centres, as has been observed 


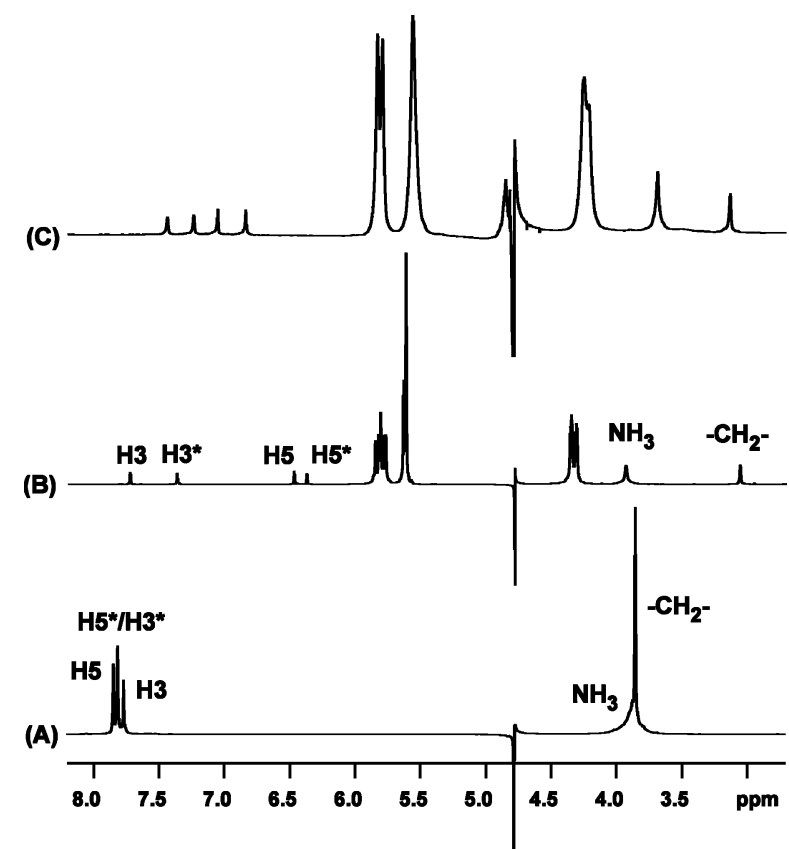

Fig. $6{ }^{1} \mathrm{H}$ NMR spectra showing (A) tri-Pt and (B) tri-Pt with added Q[7] at $R=0.5$ and $(\mathrm{C})$ tri-Pt with added Q[8] at $R=0.5$ in $\mathrm{D}_{2} \mathrm{O}$ at $25^{\circ} \mathrm{C}$.

with other cucurbituril bound guests, ${ }^{57}$ and may indicate that the cucurbituril is positioned closer to one platinum centre than the other. As the central platinum centre carries a +2 charge, it would be expected that the cucurbituril would preferentially be positioned closer to it than the mono-cationic terminal platinums. In further support of this suggestion the magnitudes of the upfield shifts of $\mathrm{H} 5^{*}$ and $\mathrm{H} 3^{*}$ are significantly larger than that of $\mathrm{H} 5$ and $\mathrm{H} 3$. This indicates that $\mathrm{H} 5^{*}$ and $\mathrm{H} 3^{*}$ are closer to the centre of the cavity than $\mathrm{H} 5$.

Fig. 7 shows the ${ }^{1} \mathrm{H}$ NMR spectrum of the hydrolysed tri-Pt (confirmed by ${ }^{195} \mathrm{Pt} \mathrm{NMR}$ ) and the metal complex with added $\mathrm{Q}[7]$ at $R>1$ (i.e. excess metal complex). In addition to the resonances observed for the free tri-Pt-aqua, small peaks are seen for the $\mathrm{Q}$ [7]-encapsulated tri-Pt-aqua. One set of tri-Pt-aqua $\mathrm{H} 5 / \mathrm{H} 5$ * and $\mathrm{H} 3 / \mathrm{H}_{3} *$ resonances $(6.30,6.32,7.38,7.40 \mathrm{ppm})$ are shifted

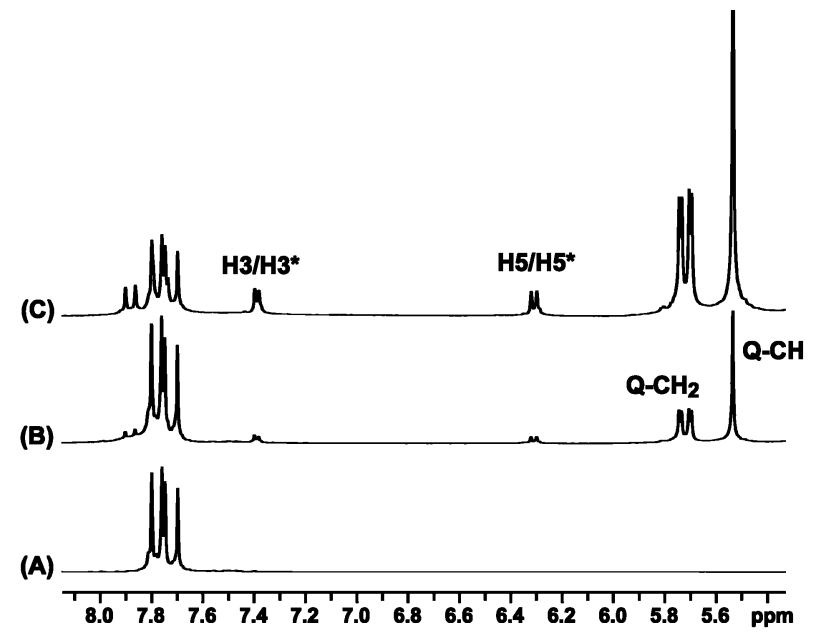

Fig. $7 \quad{ }^{1} \mathrm{H}$ NMR spectra showing (A) the hydrolysed form of tri-Pt and with added $\mathrm{Q}[7]$ at (B) $R=7.5$ and (C) $R=2.5$. upfield, while the other $\mathrm{H} 5 / \mathrm{H} 5 *$ and $\mathrm{H} 3 / \mathrm{H} 3 *$ set of resonances $(7.74,7.77,7.86$ and $7.90 \mathrm{ppm})$ do not shift or shift marginally downfield. The set of aromatic resonances that shift upfield is consistent with the respective atoms being positioned inside Q[7], and the protons from the set of resonances showing little or no downfield shifts being located outside Q[7]. This suggests that the limiting Q[7] only encapsulates one of the two dpzm ligands of tri$\mathrm{Pt}$-aqua, and, as the resonances are in the slow exchange regime, the results indicate that $\mathrm{Q}[7]$ can not pass easily over the central dicationic platinum centre.

\section{Molecular modelling}

Modelling indicated that the encapsulation of di-Pt and tri-Pt by each of the cucurbiturils was favourable compared to association at the portal or no binding at all. Encapsulation of the multinuclear platinum complexes distorted the cucurbituril from its normal spherical shape. ${ }^{46}$ The optimal geometries for encapsulation of diPt by Q[7] and Q[8] were almost symmetrical (Fig. 8), relative to the distance between the two portals, with the dpzm methylene group positioned near the centre of the cucurbituril, in terms of depth but close to the cavity wall. The dpzm-H5 protons of di-Pt are located near the three-dimensional centre of Q[7], with the corresponding $\mathrm{H} 3$ protons positioned more towards the portals, consistent with the larger upfield shift observed in NMR experiments of the $\mathrm{H} 5$ resonance upon encapsulation. As the dpzm methylene protons exhibit a smaller upfield shift than the H5 resonance, it is concluded that the maximum shielding region is located at the three-dimensional centre of the cucurbituril. Smaller upfield shifts are observed as the proton is positioned either towards the walls of the cavity or the portals. For Q[8]encapsulation, the $\mathrm{H} 5$ proton was positioned more centrally than $\mathrm{H} 3$ for only one of the two pyrazolyl groups, consistent with the smaller upfield shift observed for the $\mathrm{H} 5$ with Q[8]-encapsulation. This is due to the torsion angles around the bond between the
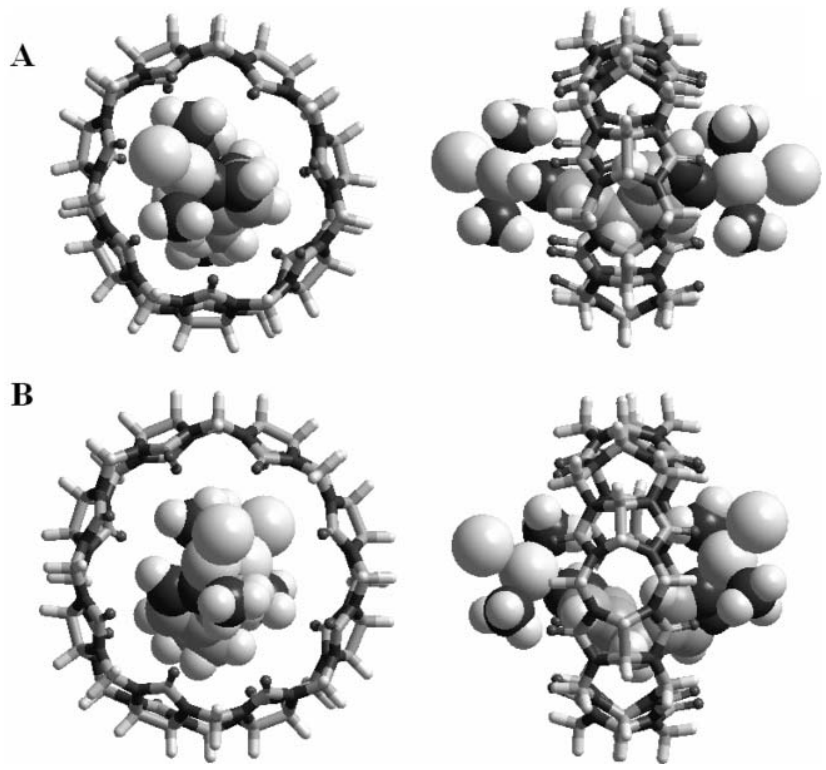

Fig. 8 Molecular model of di-Pt encapsulated in (A) Q[7] and (B) Q[8] generated using HyperChem. The platinum complex was inserted into the cucurbituril in a variety of different starting positions. Energy minimisation of the encapsulated-di-Pt was then carried out to convergence. 
pyrazolyl rings and the methylene being larger, bringing the $\mathrm{Pt}$ centres $1.4 \AA$ closer together and angling the terminal ligands back towards the $\mathrm{Q}[8]$ cavity and the $\mathrm{H} 5$ protons towards the portal (Fig. 8). The minimisation algorithm produced a similar conformation when the electrostatic component of the MM+ force field was inactivated, suggesting electrostatic interaction with the portals at most reinforced a conformation determined predominantly by hydrophobic interactions within the confines of the larger Q[8] cavity.

The binding model of tri-Pt by two Q[7] molecules (see Fig. 9) also suggested encapsulation centred on the dpzm bridging ligands, with the dpzm methylene and $\mathrm{H} 5$ protons located towards the centre, in terms of depth, but with the methylene protons again close to the cavity wall. The $\mathrm{H} 3$ protons are located inside $\mathrm{Q}[7]$, but more towards the portals than the corresponding H5, and the terminal ligands outside the portals. This conformation was consistent with the much larger upfield shift of the H5 resonances, compared to the $\mathrm{H} 3$ resonances observed in the ${ }^{1} \mathrm{H}$ NMR experiments.
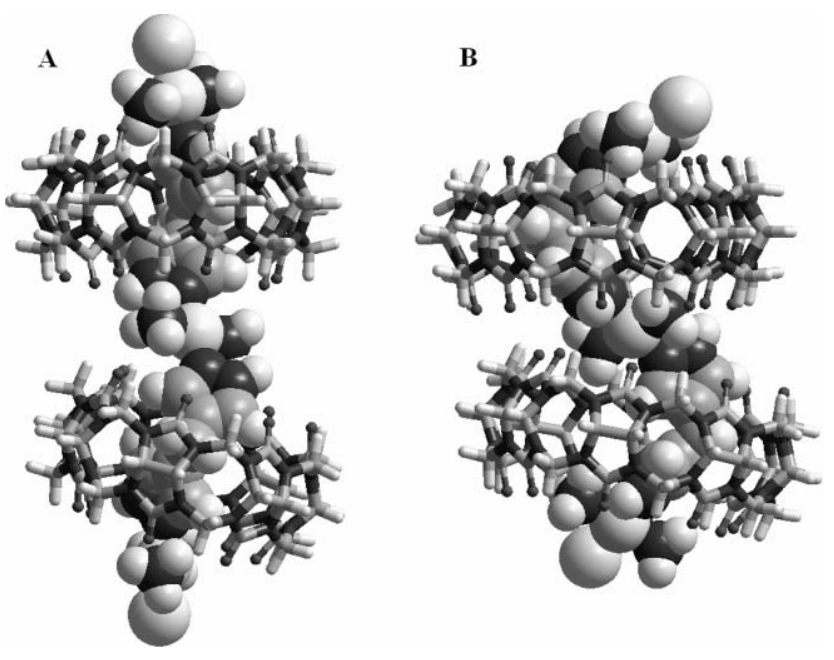

Fig. 9 Molecular model of tri-Pt encapsulated in (A) Q[7] and (B) Q[8] generated using HyperChem. The platinum complex was inserted into the cucurbituril in a variety of different starting positions. Energy minimisation of the encapsulated-tri-Pt was then carried out to convergence.

Optimised models suggested that Q[8] also preferentially encapsulated tri-Pt over the dpzm ligands (see Fig. 9); however, the smaller upfield shift of the $\mathrm{H} 5 / \mathrm{H} 5 *$ resonances and the slightly larger upfield shift of the $\mathrm{H} 3 / \mathrm{H} 3 *$ resonances upon Q[8]encapsulation suggested a different binding conformation for $\mathrm{Q}[8]$. Optimising the Q[8]-encapsulated tri-Pt geometries from different starting positions revealed energy minima that were shallower and higher relative to the global minimum than those for encapsulation by Q[7]. These minima included encapsulation of the central or terminal platinum centres, which could be accommodated, along with the ammine ligands, inside Q[8], although these conformations produced a local minima rather than the global minimum. Alternatively, when the Q[8] was centrally positioned over each dpzm, a minimised conformation could be achieved that accounted for the increased shielding of $\mathrm{H} 3$ and reduced shielding for the H5, compared to the Q[7]-encapsulation model, observed in the ${ }^{1} \mathrm{H}$ NMR spectra. The two Q[8]s are in a similar orientation but not aligned, possibly to reduce electrostatic repulsion between the portals. As a result the central platinum was at an angle to the portal of each Q[8] that allowed it to project an ammine ligand into each portal, which may have also reduced effective inter-Q[8] portal-portal repulsion, because the ammine ligands carried some of the positive charge. This angle also oriented both pyrazolyls joined to the central platinum such that each $\mathrm{N} 1$ imido proton (H1) projected out of each Q[8] cavity towards the portal of the other Q[8], enabling an additional electrostatic attraction, as the $\mathrm{H} 1$ also carried some of the positive charge. $\mathrm{H} 1$ and $\mathrm{H} 5$ are bound to adjacent atoms of the pyrazolyl ring, so such an attraction would oppose deeper $\mathrm{H} 5$ encapsulation and account for the lower upfield shift observed when encapsulated by Q[7]. The two terminal platinum centres of tri-Pt minimised to conformations with the pyrazolyl rings rotated further around the methylene bonds for a more compact form with the Pt centres and terminal ligands rotated towards the cavity and the $\mathrm{H} 5$ rotated slightly towards the portal. This dpzm-encapsulated conformation allowed the Q[8]s to come close enough to each other to encapsulate all four dpzm $\mathrm{H} 3$ protons of tri-Pt, and therefore better reflected the observed changes in the proton chemical shifts.

\section{Discussion}

This paper reports our investigation into the encapsulation of multinuclear platinum complexes by cucurbit $[n]$ uril $(\mathrm{Q}[n])$. This study was undertaken with the view that cucurbituril has the capacity to act as an effective drug delivery vehicle for the following reasons. The internal cavity is hydrophobic and capable of encapsulating the aliphatic or aromatic linking ligands of multinuclear platinum drugs. Secondly, the oxygen-rimmed portals could stabilise the encapsulation of the metal complexes through electrostatic interactions and hydrogen bonds with the platinumammine groups, and could sterically hinder attack by biological nucleophiles. It is hoped that encapsulation of metal complexes within cucurbituril will allow it to be transported through the body, minimising deactivation or degradation by nucleophilic plasma proteins. Preliminary studies have indicated that the in vivo tolerance, based on a $10 \%$ weight loss, of Q[7] when administered intravenously in mice is $200 \mathrm{mg} \mathrm{kg}^{-1}$. This is many times in excess of the amount required for a delivery system of platinum complexes that are active at the $\mathrm{mg} \mathrm{kg}^{-1}$ level. ${ }^{10,17}$

The well established anticancer drug cisplatin was initially investigated for encapsulation within Q[7]. Cisplatin as a neutral complex has two possible binding modes available with any cucurbituril, either cavity or portal binding. Portal binding can occur through stabilisation by electrostatic interactions and hydrogenbonding between the cucurbituril oxygens and the cisplatin ammine protons. The ${ }^{1} \mathrm{H}$ NMR results indicated that at least some of the cisplatin bound with medium to fast exchange kinetics, while the ${ }^{195} \mathrm{Pt}$ NMR indicated slow exchange kinetics $\left({ }^{195} \mathrm{Pt}\right.$ NMR time scale). These results suggested that some cisplatin was fully encapsulated within the cucurbituril cavity, with the remaining cisplatin presumably binding weakly at the portal. The cavity bound cisplatin is consistent with results obtained with other small neutral metal complexes, e.g. cis- $\left[\mathrm{SnCl}_{4}\left(\mathrm{H}_{2} \mathrm{O}\right)_{2}\right]$ which has been shown by X-ray crystallography to be completely encapsulated within Q[7]. ${ }^{45}$ In addition, the NMR data suggest that cis$\left[\mathrm{PtCl}\left(\mathrm{NH}_{3}\right)_{2}\left(\mathrm{H}_{2} \mathrm{O}\right)\right]^{+}$only binds Q[7] at the portals, consistent with the hydrophobic nature of the cucurbituril cavity. 
Unlike cisplatin, the multinuclear platinum complexes bound quantitatively. Previously we reported, di-Pt binds Q[7] with slow exchange kinetics with the dpzm ligand being positioned within the cucurbituril cavity. ${ }^{39}$ Here we have extended the study to include the binding of di-Pt to the larger $\mathrm{Q}[8]$ and tri-Pt binding with both $\mathrm{Q}[7]$ and $\mathrm{Q}[8]$. The resonances from di-Pt were significantly broader for encapsulation by Q[8], compared to Q[7]. This indicates that the rate of exchange between the encapsulated and free form is faster with the larger cucurbituril, and is consistent with the larger portal of Q[8] compared to Q[7]. Importantly, this result indicates that the rate of release of a multinuclear platinum complex can be modulated by the size of the cucurbituril. This could allow the balance between toxicity and cytotoxicity to be controlled, as slower release could reduce both toxicity and cytotoxicity. As expected, tri-Pt was encapsulated by Q[7] or Q[8] in a $1: 2$ ratio, with the kinetics again being slower for Q[7] than $\mathrm{Q}[8]$.

Another important difference between Q[8] and Q[7] encapsulation is the effect of the larger cavity size on the orientation of the pyrazolyl rings of the platinum complex and their relative relationship. Molecular modelling suggests that the torsion angles between the pyrazolyl rings in the dpzm ligand of di-Pt are significantly altered for $\mathrm{Q}[8]$ binding. The freedom of rotation about the $\mathrm{C}-\mathrm{C}$ bonds of the $\mathrm{CH}_{2}$ bridging group is increased in the larger cavity and as a consequence the platinum centres are retracted into the portals. The distances between the metal centres, for minimised geometry, are $\sim 10.1$ and $\sim 8.7 \AA$ for Q[7] and Q[8] respectively. This is consistent with the ${ }^{1} \mathrm{H}$ NMR results, where the ammine resonance shifted upfield upon Q[8] encapsulation but downfield with $\mathrm{Q}[7]$. The retraction of the platinum centres into the portals could result in their greater protection from nucleophilic plasma and thiol containing proteins. Furthermore, given that the minimum possible distance between the $\mathrm{Pt}-\mathrm{Pt}$ centres in vacuo is 6.6 $\AA$, further protection could be possible with even larger $\mathrm{Q}$ cavities e.g. Q[9] or $\mathrm{Q}[10] .{ }^{40}$ Similar reductions in the distances between $\mathrm{Pt}-\mathrm{Pt}$ centres were also found for the tri-Pt complexes.

$\mathrm{Q}[7]$ was shown to encapsulate the hydrolysed form of di-Pt, and based upon the similarity of the chemical shifts of the bound metal complex, it can be concluded that the cucurbituril was positioned in a similar fashion to the $\mathrm{Cl}$ form of di-Pt. However, of greater interest was the slower rate of encapsulation of the aqua form of di-Pt compared to the $\mathrm{Cl}$ form. This could be expected, given the energy cost of the +2 charge of a platinum centre passing through an electronegative cucurbituril portal to effect encapsulation of the linking dpzm ligands. Although the hydrolysed form of platinum anticancer drugs are more toxic than the corresponding $\mathrm{Cl}$ form, the very slow association/dissociation rates could result in a large decrease in toxicity, as the platinum complex would be released more slowly. While we have no data to support this possibility, the results with the aqua form of the di-Pt again highlight the potential of cucurbiturils as a platinum drug delivery system.

\section{References}

1 T. Boulikas and M. Vougiouka, Oncol. Rep., 2000, 10, 1663.

2 M. J. Piccart, H. Lamb and J. B. Vermorken, Annals of Oncology, 2001, 12, 1195.

3 E. Wong and C. M. Giandomenico, Chem. Rev., 1999, 99, 2451.

4 J. T. Hartmann and H.-P. Lipp, Expert Opin. Pharmacother, 2003, 4, 889.
5 R. D. Baird and S. B. Kaye, Eur. J. Cancer, 2003, 39, 2450.

6 L. R. Kelland, S. Y. Sharp, C. F. O'Neill, F. I. Raynaud, P. J. Beale and I. R. Judson, J. Inorg. Biochem., 1999, 77, 111.

7 M. J. Clarke, F. Zhu and D. R. Frasca, Chem. Rev., 1999, 99, 2511.

8 L. R. Kelland and S. Y. Sharp, Curr. Opin. Oncol., Endocr. Metab. Invest. Drugs, 1999, 1, 380.

9 C. X. Zhang and S. J. Lippard, Curr. Opin. Chem. Biol., 2003, 7, 481.

10 N. J. Wheate and J. G. Collins, Coord. Chem. Rev., 2003, 241, 133.

11 N. J. Wheate and J. G. Collins, Curr. Med. Chem.: Anti-Cancer Agents, $2005,5,267$.

12 N. Farrell, Y. Qu and J. D. Roberts, Top. Biol. Inorg. Chem., 1999, 1, 99.

13 S. Y. Sharp and L. R. Kelland, Curr. Opin. Oncol., Endocr. Metab. Invest. Drugs, 2000, 2, 353.

14 N. Farrell, Adv. DNA Sequence-Specific Agents, 1998, 3, 179

15 B. A. J. Jansen, J. van der Zwan, J. Reedijk, H. den Dulk and J. Brouwer, Eur. J. Inorg. Chem., 1999, 1429.

16 N. Farrell, Adv. DNA Sequence-Specific Agents, 1996, 2, 187.

17 N. Farrell, in Platinum-based Drugs in Cancer Therapy, ed. L. R. Kelland and N. P. Farrell, Humana Press, Totowa, NJ, 2000, pp. 321-338.

18 N. Farrell, Comments Inorg. Chem., 1995, 16, 373.

19 J. G. Collins and N. J. Wheate, J. Inorg. Biochem., 2004, 98, 1578.

20 N. J. Wheate, C. Cullinane, L. K. Webster and J. G. Collins, Anti-Cancer Drug Des., 2001, 16, 91.

21 A. Hegmans, Y. Qu, L. R. Kelland, J. D. Roberts and N. Farrell, Inorg. Chem., 2001, 40, 6108 .

22 P. Perego, L. Gatti, C. Caserini, R. Supino, D. Colangelo, R. Leone, S. Spinelli, N. Farrell and F. Zunino, J. Inorg. Biochem., 1999, 77, 59.

23 A. Riccardi, D. Meco, C. Ferlini, T. Servidei, G. Carelli, G. Segni, C. Manzotti and R. Riccardi, Cancer Chemother. Pharmacol., 2001, 47, 498.

24 J. D. Roberts, J. Peroutka, G. Beggiolin, C. Manzotti, L. Piazzoni and N. Farrell, J. Inorg. Biochem., 1999, 77, 47.

25 P. D. Blasi, A. Bernareggi, G. Beggiolin, L. Piazzoni, E. Menta and M. L. Formento, Anticancer Res., 1998, 18, 3113.

26 T. Servidei, C. Ferlini, A. Riccardi, D. Meco, G. Scambia, G. Segni, C. Manzotti and R. Riccardi, Eur. J. Cancer, 2001, 37, 930.

27 P. Perego, L. Gatti, S. C. Righetti, G. L. Beretta, N. Carenini, E. Corna, L. D. Bo, S. Tinelli, D. Colangelo, R. Leone, P. Apostoli, L. Lombardi, G. Beggiolin, L. Piazzoni and F. Zunino, Int. J. Cancer, 2003, 105, 617.

28 J. D. Roberts, J. Peroutka and N. Farrell, J. Inorg. Biochem., 1999, 77, 51.

29 P. Perego, C. Caserini, L. Gatti, N. Carenini, S. Romanelli, R. Supino, D. Colengelo, I. Viano, R. Leone, S. Spinelli, G. Pezzoni, C. Manzotti, N. Farrell and F. Zunino, Mol. Pharmacol., 1999, 55, 528.

30 G. Colella, M. Pennati, A. Bearzatto, R. Leone, D. Colangelo, C. Manzotti, M. G. Daidone and N. Zaffaroni, Br. J. Cancer, 2001, 84, 1387.

31 R. Villa, M. Folini, P. Perego, R. Supino, E. Setti, M. G. Daidone, F. Zunino and N. Zaffaroni, Int. J. Oncol., 2000, 16, 995.

32 C. Manzotti, G. Pratesi, E. Menta, R. Di Domenico, E. Cavalletti, H. H. Fiebig, L. R. Kelland, N. Farrell, D. Polizzi, R. Supino, G. Pezzoni and F. Zunino, Clin. Cancer Res., 2000, 6, 2626.

33 G. Pratesi, P. Perego, D. Polizzi, S. C. Righetti, R. Supino, C. Caserini, C. Manzotti, F. C. Giuliani, G. Pezzoni, S. Tongnella, S. Spinelli, N. Farrell and F. Zunino, Br. J. Cancer, 1999, 80, 1912.

34 B. Lippert (Editor) Cisplatin: Chemistry and Biochemistry of a Leading Anticancer Drug, Wiley-VCH, New York, 1999.

35 A. H. Calvert, H. Thomas, N. Colombo, M. Gore, H. Earl, L. Sena, G. Camboni, P. Liati and C. Sessa, Eur. J. Cancer, 2001, 37, S260.

36 G. Scagilotti, S. Novello, L. Crina, F. D. Marinia, M. Tonato, C. Noberasco, G. Seivaggi, F. Massoni, B. Gatti and G. Camboni, Lung Cancer, 2003, 41, S223.

37 D. I. Jodrell, T. R. J. Evans, W. Steward, D. Cameron, J. Prendiville, C. Aschele, C. Noberasco, M. Lind, J. Carmichael, N. Dobbs, G. Camboni, B. Gatti and F. D. Braud, Eur. J. Cancer, 2004, 40, 1872.

38 C. Sessa, G. Capri, L. Gianni, F. Peccatori, G. Grasselli, J. Bauer, M. Zucchetti, L. Vigano, A. Gatti, C. Minoia, P. Liati, S. V. Bosch, A. Bernareggi, G. Camboni and S. Marsoni, Annals of Oncology, 2000, 11, 977.

39 N. J. Wheate, A. I. Day, R. J. Blanch, A. P. Arnold, C. Cullinane and J. G. Collins, Chem. Commun., 2004, 1424.

40 A. I. Day, A. P. Arnold, R. J. Blanch and B. Snushell, J. Org. Chem., $2001,66,8094$. 
41 C. Marquez, U. Pischel and W. M. Nau, Org. Lett., 2003, 5, 3911. 42 W. Ong, M. Gomez-Kaifer and A. E. Kaifer, Org. Lett., 2002, 4, 1791. 43 H. J. Kim, W. S. Jeon, Y. H. Ko and K. Kim, Proc. Natl. Acad. Sci. USA, 2002, 99, 5007.

44 R. J. Blanch, A. J. Sleeman, T. J. White, A. P. Arnold and A. I. Day, Nano Lett., 2001, 2, 147.

45 S. Lorenzo, A. Day, D. Craig, R. Blanch, A. Arnold and I. Dance, CrystEng Comm, 2001, 49.

46 J. Kim, I.-S. Jung, S.-Y. Kim, E. Lee, J.-K. Kang, S. Sakamoto, K. Yamaguchi and K. Kim, J. Am. Chem. Soc., 2000, 122, 540.

47 W. L. Mock and N.-Y. Shih, J. Org. Chem., 1986, 51, 4440.

48 Y.-M. Jeon, J. Kim, D. Wang and K. Kim, J. Am. Chem. Soc., 1996, $118,9790$.

49 Y. J. Jeon, S.-Y. Kim, Y. H. Ko, S. Sakamoto, K. Yamaguchi and K. Kim, Org. Biomol. Chem., 2005, 3, 2122.
50 N. J. Wheate, J. A. Broomhead, J. G. Collins and A. I. Day, Aust. J. Chem., 2001, 54, 141.

51 N. J. Wheate, L. K. Webster, C. R. Brodie and J. G. Collins, Anti-Cancer Drug Des., 2000, 15, 313.

52 HyperChem Release 7.5 for Windows Molecular Modelling System, HyperCube Inc.: Ontario, Canada, 2004.

53 P. N. V. Pavankumar, P. Seetharamulu, S. Yao, J. D. Saxe, D. G. Reddy and F. H. Hausheer, J. Comput. Chem., 1999, 20, 365.

54 A. R. Battle, J. A. Platts, T. W. Hambley and G. B. Deacon, J. Chem. Soc., Dalton Trans., 2002, 1898.

55 D. P. Bancroft, C. A. Lepre and S. J. Lippard, J. Am. Chem. Soc., 1990, 112, 6860.

56 W. L. Mock and N.-Y. Shih, J. Org. Chem., 1986, 51, 4440.

57 H.-Y. Fu, S.-F. Xue, Q.-J. Zhu, Z. Tao, J.-X. Zhang and A. I. Day, J. Inclusion Phenom. Macrocyclic Chem., 2005, 52, 101. 